\title{
INDIRECT LAND USE CHANGE, UNCERTAINTY, AND BIOFUELS POLICY
}

Daniel A. Farber*

\begin{abstract}
Indirect land use change (ILUC)-the theory that the use of cropland for biofuels raises food prices and thus increases the incentive to convert forests and grasslands to crop production, thereby releasing stored carbon and decreasing future carbon sequestration-is a particular concern with ethanol produced from corn kernels since corn is such a major food crop (and livestock feed) and international food commodity markets are relatively inelastic. This Article examines how the Environmental Protection Agency (EPA) dealt with the uncertainty of regulating biofuels policy in the context of corn ethanol, but the lessons have broader applicability to biofuels policy and more generally to decision making under conditions of great uncertainty. The first Part discusses how biofuels may contribute to the mitigation of climate change, analyzes the U.S. statutory scheme for renewable fuels, explores the issues surrounding the statute's mandate for consideration of ILUC, and explains how EPA resolved the ILUC issue in the case of corn ethanol. The second Part probes EPA's treatment of uncertainty regarding ILUC in its decision to approve corn ethanol as a renewable fuel-primarily considering whether the broad range of emission figures used made the decision riskier, whether the central estimate used was appropriate, and whether the irreversibility of the decision should have been considered. The third Part considers the policy issues surrounding ILUC more generally-addressing whether ILUC should be considered in biofuels policy or ignored because of concerns about the reliability of models of ILUC and whether there are policy responses that might ameliorate $I L U C$ and narrow the range of uncertainty about its severity. The Article concludes that EPA acted responsibly and in good faith, however, the determination regarding ILUC for corn ethanol involved sig-
\end{abstract}

* Sho Sato Professor of Law and Chair, Energy and Resources Group, at the University of California, Berkeley. An earlier version of this paper was presented at the Second Annual EBI Biofuels Law and Regulation Conference in April 2010 and at the Berkeley Energy Biosciences Institute in October 2010. I am grateful to Anna Kantenbacher for research assistance and to Michael O'Hare for guidance in understanding biofuels issues. In addition, Dan Kammen, Michael O'Hare, and Rick Plevin provided helpful comments on earlier drafts. 
nificant errors of judgment in the treatment of uncertainty. Specifically, EPA should be more sophisticated in its treatment of uncertainty by using the means of probability distributions rather than medians, taking into account lock-in effects and real option values, and explicitly considering attention model uncertainty. EPA, however, was correct to consider ILUC despite the admitted degree of uncertainty regarding ILUC's magnitude.

Former Secretary of Defense Donald Rumsfeld famously distinguished between known knowns, known unknowns, and unknown unknowns, with the latter being the most worrisome. ${ }^{1}$ This Article probes the regulatory treatment of one of those unknowns: the possibility that displacing fossil fuels with biofuels could actually cause an increase in greenhouse gases by driving up food prices and thereby causing the destruction of far-away grasslands or forests in order to expand croplands. ${ }^{2}$

To understand this issue, some immediate background is in order. ${ }^{3}$ Biofuels are liquid fuels produced from biomass, which can be used either alone or blended with gasoline in vehicles. ${ }^{4}$ Substitution of biofuels for gasoline and other petroleum-based fuels helps reduce climate change and dependence on foreign oil. U.S. biofuels production grew by a factor of five from 2000 to 2008 , and by 2022 production is expected to triple again because of federal mandates. ${ }^{5}$ Under federal statute, the

1. Former Secretary of Defense Donald Rumsfeld explained:

"[A]s we know, there are known knowns; there are things we know we know. We also know there are known unknowns; that is to say we know there are some things we do not know. But there are also unknown unknowns - the ones we don't know we don't know. And if one looks throughout the history of our country and other free countries, it is the latter category that tend to be the difficult ones." Sec'y of Def. Donald M. Rumsfeld \& Gen. Richard Myers, Department of Defense News Briefing (Feb. 12, 2002), available at http://www.defenselink.mil/transcripts/transcript.aspx?transcriptid=2636.

2. An important recent work on this topic is Richard J. Plevin et al., The Greenhouse Gas Emissions from Biofuels' Indirect Land Use Change Are Uncertain, But May Be Much Greater than Previously Estimated (unpublished manuscript) (on file with authors). While this Article was going to press, new research appeared showing that U.S. corn exports did not decline in the first decade of the century despite a large increase in corn use for ethanol, due to increased productivity and diversion of some land from the production of other grains. See DEBO OLADOSU \& KEITH KLINE, U.S. DEP'T OF ENERGY \& OAK RIDGE NAT'L LAB., EMPIRICAL DATA AND DECOMPOSITION ANALYSIS OF U.S. CORN USE FOR ETHANOL PRODUCTION FROM 2001-2008 (Oct. 6, 2010), http:/www.arb.ca.gov/ fuels/lcfs/workgroups/ewg/101410decomposition.pdf. This empirical finding is reassuring but two provisions must be kept in mind. First, if productivity would have risen anyway, exports would have been even higher without the use of corn for fuel, lowering world food prices and reducing ILUC from its business-as-usual path. This assumes that the productivity increase would have occurred even without biofuels use for corn ethanol. Second, we do not know the repercussions of diverting land from other grain crops, which might also induce ILUC.

3. A good source for basic biofuels information is INT'L ENERGY AGENCY, BIOFUELS FOR TRANSPORT: AN INTERNATIONAL PERSPECTIVE (2004), http://www.iea.org/textbase/nppdf/free/2004/ biofuels2004.pdf.

4. Suzana Kahn Ribeiro et al., Transport and Its Infrastructure, in IPCC FOURTH ASSESSMENT Report: Climate Change 2007, Mitigation of Climate Change 323, 341 (Bert Metz et al. eds., 2007).

5. Nat'l Research Council, Nat'l ACAD. Of SCIS., Expanding Biofuel Production: AND THE TRANSITION TO ADVANCED BIOFUELS 2 (2010). This Article focuses on U.S. biofuels policy, but the European Union is also a major player. See Augusto Ninni \& Pietro Lanzini, Biofuels Policy in Europe Under the Directive 2003/30: An Analysis of Goals, Hindrances, Instruments and Effects 2 
Energy Independence and Security Act of 2007 (EISA), fuel producers are required to include increased volumes of renewable fuels until 2022, with separate quotas for cellulosic biofuels, biomass-based diesel, advanced biofuels, and total renewable fuels. ${ }^{6}$ So-called next-generation fuels - those made from plant stems, wood, and leaves, not from seeds (like biodiesel and most ethanol) or from sap (like sugar cane ethanol) would have fewer land use impacts and are the subject of intense research, including an increase of $\$ 800$ million in Department of Energy funding in 2009.' But corn-based biofuels are more than $90 \%$ of current U.S. production. ${ }^{8}$ Indirect land use change (ILUC) is a particular concern with ethanol produced from corn kernels since corn is such a major food crop (and livestock feed), and international food commodity markets are relatively inelastic.

A great deal of information is packed into the last paragraph. That information is unpacked and treated in depth in Part I of this Article. Part II probes the U.S. Environmental Protection Agency's (EPA) treatment of uncertainty regarding ILUC in its decision to classify corn ethanol as a renewable fuel. Part III then considers the policy issues surrounding ILUC more generally.

Even a casual dip into the administrative record demonstrates the extraordinary amount of time and attention that EPA devoted to its biofuels regulation, as well as the complexity of the technical issues. This Article is not intended to denigrate those efforts in any way, but at least in terms of EPA's treatment of ILUC and uncertainty, there is room for improvement. EPA's decision offers a lens through which to see important issues about biofuels, ILUC, and regulatory treatment of uncertainty. ${ }^{9}$

(Ctr. for Research on Energy and Envtl. Econ. and Policy, Working Paper No. 34, 2010), available at http://www.iefe.unibocconi.it (follow "Working Papers" hyperlink). The relevance of ILUC to EU policy is considered in CATHERINE BOWYER, INST. FOR EUROPEAN ENVTL. POLICY, ANTICIPATED INDIRECT LAND USE CHANGE ASSOCIATED WITH EXPANDED USE OF BIOFUELS AND BIOLIQUIDS IN the EU-AN ANalysis of the National Renewable EnERgy action Plans (2010), http://www.ieeplondon.org.uk/publications/pdfs/2010/iluc_analysis.pdf. On the international trade implications of biofuels policy, see Cymie Payne, Local Meets Global: The Low Carbon Fuel Standard and the WTO, 34 N.C. J. INT'L L. \& COM. REG. 891 (2009).

6. NAT'L RESEARCH COUNCIL, supra note 5, at 5-6.

7. Id. at 11. For some concerns about the difficulty of scaling up cellulosic production, see Robert F. Service, Is There a Road Ahead for Cellulosic Ethanol?, 329 SCIENCE 784 (2010). Potential feedstocks are discussed in Chris Somerville et al., Feedstocks for Lignocellulosic Biofuels, 329 SCIENCE 790 (2010). According to the U.S. Department of Agriculture, corn ethanol now produces more energy than is required to make it, a welcome development. See Katherine Ling, Corn Ethanol Goes from "Energy Sink" to "Substantial Net Energy Gain," E\&E NEws (June 21, 2010), http://www.eenews.net/eenewspm/print/2010/06/21/3.

8. NAT'L RESEARCH COUNCIL, supra note 5, at 29. According to one estimate, ethanol could reduce greenhouse gas emissions by twelve percent relative to gasoline, not taking into account ILUC. See Jason Hill et al., Environmental, Economic, and Energetic Costs and Benefits of Biodiesel and Ethanol Biofuels, 103 Proc. NAT'L ACAD. OF SCI. 11206, 11208 (2006).

9. For a more general discussion of the treatment of uncertainty in the regulatory process, see Daniel A. Farber, Uncertainty, 99 GEO. L. J. (forthcoming 2011). 
While the regulatory scheme and the analytic issues are formidable, the ILUC issue is not merely a technical footnote to biofuels policy. If ILUC turns out to be high, we may find that biofuels policy has failed to produce the intended goal of significant reduction of greenhouse gases. It might even boomerang and produce increased global carbon emissions. And worse yet, it may have worsened the situation of the world's hungriest groups. On the other hand, if we pass up the use of biofuels, we may later find that we have missed an opportunity for controlling climate change. What makes this issue particularly knotty is that we cannot be sure of the extent of ILUC. This Article focuses on how EPA has dealt with this conundrum in the context of corn ethanol, but the lessons have broader applicability to biofuels policy and more generally to decision making under conditions of great uncertainty.

As we will see, EPA made a start on analyzing uncertainty by deriving a probability distribution for ILUC based on possible parameter val-

ues. Having done so, however, it used the wrong statistic as the basis for its decision, and it failed to take into account the irreversible effects of an erroneous finding in favor of corn ethanol. But it was right to ignore risk aversion, and even more importantly, it was right to conclude that uncertainty was no justification for ignoring ILUC. These are points that apply well beyond the narrower issue of corn ethanol's status as a renewable fuel.

\section{BIOFUELS AND THE RENEWABLE FUEL STANDARD (RFS)}

This Part provides the basis for the later analysis. It begins with a discussion of how biofuels may contribute to the mitigation of climate change. It then analyzes the U.S. statutory scheme for renewable fuels ${ }^{10}$ and explores in detail the issues surrounding the statute's mandate for consideration of ILUC. Finally, it takes a close look at how EPA resolved the ILUC issue in the case of corn ethanol.

\section{A. Biofuels as a Component of Climate Change Mitigation}

Although biofuels may be useful in reducing dependence on foreign oil, their primary purpose is to reduce carbon emissions and restrain climate change. The need for climate change mitigation is clear. According to the latest Intergovernmental Panel on Climate Change (IPCC) report, global concentrations of greenhouse gases "have increased markedly as a result of human activities since 1750 and now far exceed pre-industrial values determined from ice cores spanning many thou-

10. The U.S. scheme is placed in an international context in Jody M. Endres, Clearing the Air: The Meta-Standard Approach to Ensuring Biofuels Environmental and Social Sustainability, 28 VA. ENVTL. L.J. 73 (2010). 
sands of years." The best current estimate is that a doubling of carbon dioxide $\left(\mathrm{CO}_{2}\right)$ from pre-industrial levels would result in a temperature increase of between $1.5^{\circ} \mathrm{C}$ and $4.5^{\circ} \mathrm{C}\left(1.8\right.$ to $\left.5.4^{\circ} \mathrm{F}\right)$ by the end of this century. ${ }^{12}$ The resulting rise in sea level could result in loss of coastal lands, ${ }^{13}$ salt water invasion of some estuary systems, salt water intrusions into some drinking sources, and increased exposure to flood damage. ${ }^{14} \mathrm{~A}$ half-meter sea level rise would place $\$ 185$ billion worth of property in jeopardy by 2100 , and the cost of protecting developed areas from a halfmeter rise would be $\$ 50$ to $\$ 66$ billion. $^{15}$

Reducing emissions of greenhouse gases is the key to limiting these harmful impacts. As of 2004, transportation produced nearly one quarter of world energy-related $\mathrm{CO}_{2}$ emissions. ${ }^{16}$ Energy use for transportation is projected to grow dramatically over the next fifty years, more than doubling between 2010 and $2050 .{ }^{17}$ U.S. energy use for transportation could rise by $46 \%$ between 2002 and $2025 .{ }^{18}$ Biofuels are a promising method for reducing transportation-related emissions. ${ }^{19}$ At the global level, biofuels could produce about $10 \%$ of transportation fuels by $2030 .^{20}$ The potential for biofuels to contribute to climate mitigation is highincluding between five hundred and twelve hundred megatons of $\mathrm{CO}_{2}$ by 2030 from bioethanol (leaving aside ILUC). ${ }^{21}$

Several types of biofuels are now in use or in development. Ethanol from sugar cane has been used successfully in Brazil. ${ }^{22}$ In the United States, ethanol from corn is dominant..$^{23}$ In the future, conversion of

11. Richard B. Alley et al., Summary for Policymakers, in IPCC FOURTH ASSESSMENT REPORT: Climate Change 2007, The Physical SCIEnCE Basis 1, 2 (Susan Solomon et al. eds., 2007).

12. See Richard A. Kerr, Latest Forecast: Stand By for a Warmer, but Not Scorching, World, 312 SCIENCE 351 (2006).

13. See A. Barrie Pittock, Climate Change: Turning Up the Heat 262-82 (2005) (providing examples, including China, India, Pakistan, Bangladesh, and the United States).

14. See Elizabeth Kolbert, Field Notes from a Catastrophe: Man, Nature, and Climate CHANGE 123-24 (2006) (reporting that what are now one-hundred-year floods could become routine by late in this century); see also PITTOCK, supra note 13, at 118 box 5 (stating that without adaptive measures, annual flood losses would increase from $£ 1$ to $£ 27$ billion in different scenarios).

15. William E. Easterling iII et al., Pew Ctr. on Global Climate Change, Coping with Global Climate Change: The Role of Adaptation in the United States 14 (2004), http:/www.pewclimate.org/docUploads/Adaptation.pdf.

16. See generally David ARcher \& Stefan Rahmstorf, The Climate CRISIS: AN INTRODUCTORY GUIDE TO CLIMATE CHANGE 205 (2010) (explaining that transportation uses $24 \%$ of all energy production).

17. Ribeiro et al., supra note 4 , at 333 , fig.5.3.

18. Id. at 333 .

19. Other possible uses of biofuels also exist but are outside the scope of this Article. For instance, biofuels could be used to produce biogas. See FELIX R. FITZROY \& ElISSAIOS PAPYRAKIS, AN InTRODUCTION TO ClimATE CHANGE ECONOMICS AND POLICY 40-41 (2010).

20. Ribeiro et al., supra note 4 , at 326.

21. Id. at 343 .

22. Id. at 341 .

23. Id. The U.S. ethanol industry is heavily dependent on tax incentives. See BRENT D. Yacobucci, Cong. Research Serv., RL 33290, Fuel Ethanol: Background and Public POLICY ISSUES 12 (2008). Most notable is a $\$ 0.51$ tax credit for every gallon of blended gasoline. Brent D. Yacobucci \& ToM Capehart, Cong. Research Serv., RL 34265, Selected Issues 
grasses or woody plants into biofuels is said to be the most attractive technology because cellulosic crops have high yields, can be grown "in areas unsuitable for grains and other food/feed crops and thus do not compete with food," and use relatively little energy in their production. ${ }^{24}$ By 2030 , use of cellulosic ethanol could eliminate up to 300 megatons of carbon emissions from fossil fuels. ${ }^{25}$ Biodiesel is perhaps less promising but does have some potential. ${ }^{26}$

Different production methods and crop sources can yield very different greenhouse benefits. On a well-to-wheels basis (that is, from the extraction of the fuel used in farming to combustion in a vehicle), ethanol from sugar cane such as that produced in Brazil produces significant greenhouse gas reductions. ${ }^{27}$ But if the same product-ethanol-is produced from corn, its greenhouse gas benefits are at best much smaller. ${ }^{28}$ Estimates range from higher emissions from corn ethanol than from gasoline, down to an emissions reduction of $30 \%$ compared to gasoline, with a $13 \%$ emission reduction as the best estimate as of $2007 . .^{29}$ As we will see later, EPA is somewhat more optimistic about corn ethanol in the future, given improvements in production efficiencies. ${ }^{30}$ It should be noted that the problem is not that corn is in some way a defective plant source, but rather that "corn farming and processing are energy intensive." 31 The next Section shows how the varying qualities of different types of biofuels are factored into the federal regulatory scheme.

\section{B. The Statutory Scheme}

EPA's renewable fuel regulation was both authorized and constrained by a congressional mandate. That mandate stemmed from EISA. $^{32}$ EISA's renewable fuel mandate is now part of Section 211(o) of the Clean Air Act. ${ }^{33}$ Unfortunately, we need to delve into the statute's

\footnotetext{
RELATED TO AN EXPANSION OF THE RENEWABLE FUEL STANDARD (RFS) 6 (2008). Imported ethanol is subject to a $\$ 0.54$ duty. Id. at 7 . For a sharp criticism of these subsidies, see Arnold W. Reitze, Jr., Biofuels -Snake Oil for the Twenty-First Century, 87 OR. L. REV. 1183, 1218-34 (2008). Despite the title, Reitze devotes his ire primarily to corn ethanol and is more favorable toward cellulosic fuels. See id. at 1258.

24. Ribeiro et al., supra note 4 , at 342 .

25. Id. at 343 .

26. Id.

27. Id. at 344 .

28. Id.

29. Id.

30. See infra notes $76-77$ and accompanying text.

31. Ribeiro et al., supra note 4 , at 344.

32. Energy Independence and Security Act of 2007, Pub. L. No. 110-140, § 202, 121 Stat. 1492, 1521-22. For an overview of issues relating to EISA, see RANDY SCHNEPF \& BRENT D. YACOBUCCI, CONG. Research Serv., R40155, Renewable Fuel STANDARd (RFS): OVERVIEW aNd IsSUES (2010).

33. 42 U.S.C. $\$ 7545($ o) (2006 \& Supp. II 2008).
} 
rather complicated provisions in some detail in order to evaluate EPA's decision regarding corn ethanol. ${ }^{34}$

Section 7545(o)(1) defines various categories of fuels, including renewable fuels, advanced biofuels, and cellulosic biofuels. ${ }^{35}$ Under $\S 7545(\mathrm{o})(2)(\mathrm{A})$, EPA must promulgate regulations that ensure that specified volumes of these various types of biofuels are used within the United States instead of gasoline or diesel..$^{36}$ The initial (2006) and final (2022) requirements ${ }^{37}$ are summarized in the following table:

\begin{tabular}{|c|c|c|c|c|c|}
\hline \multirow{2}{*}{$\begin{array}{l}\text { Fuel } \\
\text { Type }\end{array}$} & $\begin{array}{l}\text { Required } \\
\text { Emissions }\end{array}$ & \multicolumn{2}{|c|}{$\begin{array}{c}\text { Initial } \\
\text { Requirement }\end{array}$} & \multicolumn{2}{|c|}{$\begin{array}{c}\text { Final } \\
\text { Requirement }\end{array}$} \\
\hline & $\begin{array}{c}\text { Percentage } \\
\text { below gasoline } \\
\text { baseline }\end{array}$ & $\begin{array}{l}\text { Quantity } \\
\text { (gallons) }\end{array}$ & Year & $\begin{array}{l}\text { Quantity } \\
\text { (gallons) }\end{array}$ & Year \\
\hline $\begin{array}{l}\text { Renewable } \\
\text { fuels }\end{array}$ & $20 \%$ & 9.0 billion & 2008 & 36 billion & 2022 \\
\hline $\begin{array}{l}\text { Advanced } \\
\text { biofuels }\end{array}$ & $50 \%$ & 0.6 billion & 2009 & 21 billion & 2022 \\
\hline $\begin{array}{l}\text { Cellulosic } \\
\text { biofuels }\end{array}$ & $60 \%$ & 0.1 billion & 2010 & 16 billion & 2022 \\
\hline
\end{tabular}

By 2017, use of renewable and alternate fuels is scheduled to increase by a factor of seven from 2006 levels, which will probably require significant technological progress. ${ }^{38}$ Use of corn ethanol to fill the requirements is capped after 2015 at fifteen billion gallons. ${ }^{39}$

For present purposes, the critical issue is fuel classification. Different biofuels must attain certain specified percentage reductions in green-

34. For an overview of the provisions, see FRED SISSINE, CONG. RESEARCH SERV., RL 34294, ENERGY INDEPENDENCE AND SECURITY ACT OF 2007: A SUMMARY OF MAJOR PROVISIONS (2007). EISA also addressed other significant issues such as fuel economy standards for vehicles and appliance and lighting efficiency standards. Id. at 1-2. The enactment process is described in id. at 3-4.

35. 42 U.S.C. $\$ 7545(0)(1)$

36. Id. $\$ 7545(\mathrm{o})(2)(\mathrm{A})$.

37. Meeting the 2022 requirement will require a $\$ 167$ billion investment in 527 new biorefineries, along with new blender pumps for gas stations. See Allison Winter, USDA Outlines Strategy for Meeting 2022 Renewable-Fuels Goals, E\&E NEws (June 22, 2010), http://www.eenews.net/eenewspm/ 2010/06/22/05

38. See YACOBUCCI, supra note 23, at 11.

39. YACOBUCCI \& CAPEHART, supra note 23 , at 3. 
house gas emissions in order to qualify for each classification. ${ }^{40}$ For instance, under $\$ 7545(\mathrm{o})(1)(\mathrm{B})(\mathrm{i})$, an "advanced biofuel" must have greenhouse gas emissions at least $50 \%$ below "baseline lifecycle greenhouse gas emissions" - the baseline is defined in $\S 7545(\mathrm{o})(1)(\mathrm{C})$ to mean average lifecycle emissions for "gasoline or diesel (whichever is being replaced by the renewable fuel) sold or distributed as transportation fuel in 2005." 41

Classification of biofuels is based on lifecycle analysis (LCA). In conducting such an analysis, $\S 7545(\mathrm{o})(1)(\mathrm{H})$ tells us, EPA must consider:

[T]he aggregate quantity of greenhouse gas emissions (including direct emissions and significant indirect emissions such as significant emissions from land use changes) ... related to the full fuel lifecycle, including all stages of fuel and feedstock production and distribution, from feedstock generation or extraction through the distribution and delivery and use of the finished fuel to the ultimate consumer ...."42

It is particularly important for our purposes that this subsection requires EPA to consider "significant emissions from land use changes." 43

To qualify as a renewable fuel, any fuel produced from any new facility that began construction after the statute's enactment date must achieve at least a $20 \%$ reduction in greenhouse gases compared with the gasoline baseline, according to $\S 7545(\mathrm{o})(2)(\mathrm{A})(\mathrm{i}){ }^{44}$ Note the implicit grandfathering for existing facilities, whose output can qualify as renewable without meeting the $20 \%$ requirement. EPA has some power to adjust percentages, but this adjustment authority is also subject to grandfathering under $\$ 7545(\mathrm{o})(4)(\mathrm{G})$ :

If the Administrator adjusts, or revises, a percent level referred to in this paragraph or makes a change in the analytical methodology used for determining the lifecycle greenhouse gas emissions, such adjustment, revision, or change (or any combination thereof) shall only apply to renewable fuel from new facilities that commence construction after the effective date of such adjustment, revision, or change. ${ }^{45}$

Thus, if EPA reconsiders its methodology for determining (say) the $20 \%$ threshold for renewable fuels, the change can only affect the classification of fuels produced by plants that are built after the effective date

40. The carbon intensity of gasoline is known within a small range, though gasoline from unconventional sources like oil shale and oil sands is more carbon intensive than the average gasoline of today.

41. 42 U.S.C. $\$ 7545(0)(1)(B)(i),(o)(1)(C)$

42. Id. $\S 7545(\mathrm{o})(1)(\mathrm{H})$.

43. Id.

44. Id. $\$ 7545(\mathrm{o})(2)(\mathrm{A})(\mathrm{i})$.

45. Id. $\$ 7545(\mathrm{o})(4)(\mathrm{G})$. 
of the change. ${ }^{46}$ In short, it would appear that, if a plant's production qualifies as a renewable fuel or under some other category when it was built, changes in regulations after that time do not affect the classification. We will return to the grandfathering issue later.

Recall that EPA is required to consider ILUC in determining a fuel's status under the RFS. That issue was the most difficult facing EPA and is the focus of this Article. ${ }^{47}$ The next Section explains how ILUC works and why it is such an important concern.

\section{The ILUC Issue}

Indirect land use change is not an obvious direct effect of biofuels (at least to most people), nor was it obvious that the magnitude of ILUC would be significant. Only in the past few years has this issue really emerged.

A research team led by Timothy Searchinger of Princeton's Woodrow Wilson School sparked the debate about ILUC in a seminal 2008 article. ${ }^{48}$ The basic theory is simple: use of cropland for biofuels raises food prices and increases the incentive to convert forests and grasslands to crop production, thereby releasing stored carbon and decreasing future carbon sequestration. ${ }^{49}$ Note that the effect is mediated by world food and fiber prices and therefore requires no geographic link between the land used for biofuels and the land converted to crops. The biofuels crops could be grown in Illinois, while the forest could be lost in Brazil through a "chain of dominoes" including displacement of U.S. soybeans by corn, displacement of cattle by soybeans in Brazil, and displacement of forest by cattle raising - all resulting in large $\mathrm{CO}_{2}$ discharges from burning and decay of plant and soil carbon stocks. Given that $20 \%$ of the U.S. corn crop went to ethanol production by $2006,{ }^{50}$ these effects could well be significant. According to the Congressional Research Service, the "ethanol-driven surge in corn demand has been associated with a sharp rise in corn prices." 1

46. Given that this provision is part of $\$ 7545(0)(4)$, it might be construed (like the rest of the subsection) as relating only to adjustments that relax the requirements of the statute. The language regarding adjustments in methodology is not so limited, however, and seems to apply to all changes in methodology, regardless of direction. It would make little sense to make a regulatory shield, such as $\S 7545(\mathrm{o})(4)(\mathrm{G})$, available only to new plants rather than existing ones. The Section can be read much more sensibly to shield existing plants from the effects of adverse changes in EPA's methodology.

47. Other policy issues and environmental concerns relating to ethanol are discussed in Zachary M. Wallen, Far from a Can of Corn: A Case for Reforming Ethanol Policy, 52 ARIZ. L. REV. 129 (2010).

48. Timothy Searchinger et al., Use of U.S. Croplands for Biofuels Increases Greenhouse Gases Through Emissions from Land-Use Change, 319 SCIENCE 1238 (2008).

49. Id. at 1238.

50. YACOBUCCI \& CAPEHART, supra note 23, at 1-2.

51. Id. at 6 . For an overview of lifecycle analysis and ILUC, see BRENT D. YACOBUCCI \& KELSI S. BRACMORT, CONG. RESEARCH SERV., RL 40460, CALCUlATION OF LiFECyCle GREENHOUSE GaS EMISSIONS FOR THE RENEWABLE FUEL STANDARD (2009). A detailed examination of particular ILUC models is presented in ROBERT EDWARDS ET AL., INDIRECT LAND USE CHANGE FROM 
Searchinger and his colleagues made several key observations. First, ILUC is reduced because dry distillers' grains, produced as a byproduct of biofuels production, replace part of the animal feed that is otherwise produced directly from corn. Hence, they estimate that when an acre is used for ethanol, only about two-thirds of another acre needs to be brought into corn production to supply feed markets. ${ }^{52}$

Second, biofuels production in the United States would reduce American food exports. ${ }^{53}$ Consequently, "[w]hen other countries replace U.S. exports, farmers must generally cultivate more land per ton of crop because of lower yields." 54 Thus, in general, if an acre's worth of food production in the United States is lost, more than an acre of land will have to be added to food production elsewhere in the world to make up the difference.

Third, the carbon cost resulting from ILUC is incurred immediately when cropland is converted to biofuels; this cost is gradually paid back if the fuels are otherwise less carbon-intensive than gasoline. For corn ethanol, Searchinger et al. estimate that "[o]ver a 30-year period, counting land-use change, GHG emissions from corn ethanol nearly double those from gasoline for each $\mathrm{km}$ driven." 55 They estimate a carbon payback period of 167 years for corn ethanol. ${ }^{56}$ In effect, ILUC is part of the initial investment in producing biofuels, so the resulting biofuels capacity has to be used in part to pay off the carbon debt incurred at the beginning.

An obvious response to the Searchinger findings would be a call to protect grasslands and forests from conversion to cropland. Searchinger argues, however, that "[c]ounteracting increases in biofuels with controls or disincentives against land conversion would not only face great practical challenges but also have harsh social consequences." 57 All other things being equal, the problem is that reducing croplands means reducing food supplies, resulting in "poorer diets in developing countries." 58 In addition, decisions about protecting rainforests in other countries are under the control of other sovereigns, not of the American policymakers who must decide on U.S. biofuel policy.

The logic of ILUC seems undeniable: because demand for food is relatively inelastic, less U.S. food production means higher food and fi-

INCREASED BIOFuels DEMAND (2010) (European Commission Institute for Energy), http:// ec.europa.eu/energy/renewables/consultations/doc/public_consultation_iluc/study_4_iluc_modelling_c omparison.pdf.

52. Searchinger et al., supra note 48 , at 1238.

53. Id.

54. Id.

55. Id. at 1239. The choice of time period for evaluating ILUC has an important effect on the results. For discussion, see M. O'Hare et al., Proper Accounting for Time Increases Crop-Based Biofuels' Greenhouse Gas Deficit Versus Petroleum, 4 ENVTL. RES. LETTERS 1 (2009), http://iopscience. iop.org/1748-9326/4/2/024001/pdf/1748-9326_4_2_024001.pdf.

56. Searchinger et al., supra note 48 , at 1239 .

57. Id. at 1240 .

58. Id. 
ber prices, which in turn encourage production increases elsewhere in the world. It is also plausible to assume that at least some of those production increases would come in the form of increasing agricultural acreage by conversion of forests and grasslands, rather than increased yields on existing croplands. ${ }^{59}$ The key question is the size of these effects. Prompted by Searchinger's findings, other research teams addressed the magnitude of ILUC. ${ }^{60}$

At this writing, the most recent estimate in the peer reviewed literature is by a joint Berkeley-Purdue team led by Thomas Hertel. ${ }^{61}$ Their estimate is roughly one quarter the size of Searchinger's ${ }^{62}$ The differences are not due to any major conceptual disputes but rather to different parameter estimates. They calculated lower and upper bounds of 14.7 and $90 .^{63}$ The upper bound is still below Searchinger's estimate of $104 \mathrm{gCO}_{2} / \mathrm{MJ}$, but not by much. Note that the upper bound is about sixty grams above their best estimate of twenty-seven grams, whereas the lower bound is about thirteen grams below. It is also worth noting that Hertel's team calculated a "food neutral" estimate of about 38 $\mathrm{gCO}_{2} / \mathrm{MJ}^{64}$ This means that actual ILUC is lowered below the foodneutral level because production of biofuels on croplands results in global food consumption decreases - not good news for the world's poor.

The Hertel team also provides a very useful discussion of the uncertainties surrounding ILUC estimates. They note that the "uncertainty in our estimates is not symmetric: Actual discharges may be much larger than our central value in more ways than they may be smaller, as many of the effects we observe are bounded by zero on the left." 65 Consequently, they say, "[b]etter understanding of skewness and long tails in an estimated distribution of the ILUC value will probably imply that an optimal value for the index assigned to a particular biofuel will be different from a central estimator of its ILUC effect." ${ }_{66}$ For those not fluent in

59. An additional complication is that increased yields might mean greater cultivation (requiring additional fuel for the tractor) or fertilization (which can release greenhouse gases). Thus, increased yield of food crops can also add to the carbon debt caused by conversion of cropland to biofuels production.

60. Plevin et al., supra note 2, at 4 (citing figures with ranges of 20-200, 15-90, 24-104, 36-53, and $21-118 \mathrm{gCO}_{2} / \mathrm{MJ}$, including some studies of EU corn ethanol).

61. Thomas W. Hertel et al., Effects of US Maize Ethanol on Global Land Use and Greenhouse Gas Emissions: Estimating Market-Mediated Responses, 60 BIOSCIENCE 223 (2010).

62. Id. at 223. More recent unpublished results from some members of the same team resulted in a larger range of uncertainty - from 34-111 $\mathrm{gCO}_{2} / \mathrm{MJ}$ using one statistical distribution. However, they considered values up to $370 \mathrm{gCO}_{2} / \mathrm{MJ}$ as also potentially possible. Plevin et al., supra note 2 , at $16-17,20$ ("[G]iven the range of estimates generated by the plausible parameters used in this study, a value much higher than the values estimated by CARB and USEPA appears more likely than a value below those estimates.").

63. Hertel et al., supra note 61 , at 230 . I divided the upper and lower bounds of 440 and 2700 given in the paper by 30 in order to annualize the carbon increase over the same time period as Searchinger.
64. Id. Again, I divided by 30 in order to annualize as in the previous note.
65. Id.
66. Id. 
statistical jargon, this last sentence refers to the fact that high-side outcomes are likely to be larger than low-side errors (the "skew") and that some of the high-side outcomes could be doozies (the "long tail"). We will consider later the implications of this point for policymakers.

\begin{tabular}{|c|c|c|}
\hline & $\begin{array}{c}\text { Annualized ILUC } \\
\text { (Best Estimate) }\end{array}$ & Year \\
\hline $\begin{array}{c}\text { Searchinger } \\
\text { et al. }\end{array}$ & $104 \mathrm{gCO}_{2} / \mathrm{MJ}$ & 2008 \\
\hline $\mathrm{CARB}^{67}$ & $30 \mathrm{gCO}_{2} / \mathrm{MJ}$ & 2009 \\
\hline Hertel et al. & $27 \mathrm{gCO}_{2} / \mathrm{MJ}$ & 2010 \\
\hline
\end{tabular}

A simpler approach to estimating ILUC is to assume that land taken out of food production has been used in some fixed proportion for exports and that foreign producers will only have to replace the loss in those exported crops. ${ }^{68}$ Note that this estimate ignores price effects and assumes that both demand and total global production will remain the same. Estimates on this basis provide a range of results from a $50 \%$ increase in emissions compared with gasoline to a $16 \%$ reduction, with a central estimate of a $17 \%$ increase in emissions. ${ }^{69}$

ILUC is not the only negative impact of biofuels. The potential impact on food supply, noted by Searchinger, is particularly troubling because food needs are expected to increase sharply. According to demographic projections, by mid-century another three billion people will have been added to the world population, while arable land will probably remain constant. ${ }^{70}$ Climate change will also place serious stress on agriculture, particularly in places where temperatures rise above $30^{\circ} \mathrm{C}$ $\left(86^{\circ} \mathrm{F}\right)$. To the extent that arable land is used for biofuels production, less is left for food production. ${ }^{71}$ Hence, "it will be increasingly difficult to maintain, much less increase, yields of our current major crops as tem-

67. The California Air Resources Board (CARB) figure can be found at http://www.arb.ca.gov/ fuels/lcfs/121409lcfs_lutables.pdf.

68. RenEwable FuELS AGENCY, THE Gallagher REVIEW OF THE INDIRECT EFFECTS OF BIOFUELS PRODUCTION 48 (2008). The report urged a slowdown in deployment of biofuels until the uncertainties regarding ILUC could be addressed. Id. at 8 .

69. Id. at 51 .

70. N.V. Fedoroff et al., Radically Rethinking Agriculture for the 21st Century, 327 SCIENCE 833, $833(2010)$.

71. See id. 
peratures rise and drylands expand."72 Expanded use of biofuels may divert land from food production, worsening an already difficult food challenge. ${ }^{73}$

EPA is charged with addressing environmental issues, not world hunger. But, as we have seen, its mandate under EISA does include consideration of ILUC, which proved to be a vexing issue.

\section{EPA, Ethanol, and Uncertainty}

EPA's formal implementation of EISA was nearly a yearlong process. The formal procedure began in May of 2009, when EPA announced its consideration of new RFS regulations. ${ }^{74}$ On May 26, 2009, the Notice of Proposed Rulemaking was published in the Federal Register. ${ }^{75}$ EPA's proposed analysis was not favorable to corn ethanol.

EPA considered it appropriate to include foreign direct and indirect emissions in the analysis. ${ }^{76}$ Considering a variety of technology improvements that could increase the efficiency of production for corn ethanol, EPA concluded:

Combining all of these technologies in a state-of-the-art natural gas powered corn ethanol facility would produce ethanol that has approximately $35 \%$ less lifecycle GHG emissions than an energy equivalent amount of baseline gasoline displaced over 100 years using a $2 \%$ discount rate and, by comparison a $14 \%$ reduction when accounting for 30 years of emission changes but applying no discounting. ${ }^{77}$

It seems unrealistic to assume that the relatively unsophisticated biofuels would remain in use for one hundred years; even thirty years may be a stretch. Using the thirty-year figure left corn ethanol $6 \%$ below

72. Id. For a discussion of potential methods for meeting the challenge see Special Section: Food Security, 327 SCIENCE 797, 797-834 (2010).

73. See Rosamond L. Naylor et al., The Ripple Effect: Biofuels, Food Security, and the Environment, 49 ENV'T 31, 41 (2007); David Pimentel \& Tad Patzek, Ethanol Production: Energy and Economic Issues Related to U.S. and Brazilian Sugarcane, 16 NAT. RESOURCES RES. 235, 241 (2007) ("[E]xpansion of ethanol production in the U.S. and Brazil is having negative impacts on food production and food exports...."). Another potential negative impact is increased stress on water supplies. See Robert F. Service, Another Biofuels Drawback: The Demand for Irrigation, 326 SCIENCE 516, 51617 (2009).

74. U.S ENVTL. Prot. Agency, EPA-420-F-09-023, EPA Proposes New Regulations for THE NATIONAL RENEWABLE FuEl STANDARD PROGRAM FOR 2010 AND BEYOND (2009).

75. Regulation of Fuels and Fuel Additives: Changes to Renewable Fuel Standard Program, 74 Fed. Reg. 24,904 (proposed May 26, 2009) (to be codified at 40 C.F.R. pt. 80).

76. The Notice of Proposed Rulemaking provided:

While there is clearly significant uncertainty in determining the specific degree of land use change and the specific impact of those changes, there is considerable overall certainty as to the existence of the land use changes in general, the fact that GHG emissions will result, and the cause and effect linkage of these emissions impacts to the increased use of feedstock for production of renewable fuels.

Id. at 25,024.

77. Id. at 25,042 . 
the level needed to qualify as a renewable fuel. This was obviously not the result Midwest farmers had been hoping for.

EPA changed its position on corn ethanol in the final rule. A crucial graph (reproduced in the Appendix) shows EPA's view of the range of uncertainties. ${ }^{78}$ EPA explained regarding this graph that:

Figure V.C-1 shows the percent change in the lifecycle GHG emissions compared to the petroleum gasoline baseline in 2022 for a corn ethanol dry mill plant using natural gas for its process energy source, drying the national average of $63 \%$ of the DGS it produces and employing corn oil fractionation technology. Lifecycle GHG emissions equivalent to the gasoline baseline are represented on the graph by the zero on the $\mathrm{X}$-axis. The $20 \%$ reduction threshold is represented by the dashed line at -20 on the graph. ${ }^{79}$

The key conclusion is that "the midpoint of the range of results is a $21 \%$ reduction in greenhouse gas emissions compared to the gasoline 2005 baseline." 80 But, there is considerable uncertainty about ILUC from corn ethanol: "The $95 \%$ confidence interval around that midpoint ranges from a $7 \%$ reduction to a $32 \%$ reduction compared to the gasoline baseline" based on the uncertainty in the land use change assumptions. ${ }^{81}$ The table in the Appendix provides a summary of these figures.

Based on the table and graph, the range of possible greenhouse gas reductions appears to run from zero to forty-two, giving the midpoint of twenty-one. Note that the distribution is a bit asymmetrical: the midpoint is twenty-one, the lower end of the confidence interval is fourteen points lower, but the high end of the confidence interval is only eleven points higher than the midpoint. These numbers represent reductions, so that what this asymmetry means is that the deviations from the midpoint in the "bad" direction (lesser reductions in greenhouse gases) are greater than deviations in the "good" direction (greater than expected reductions in greenhouse gases).

As we will see, EPA's decision to use the midpoint of the distribution was significant (and questionable). EPA explained the decision as follows:

In analyzing the corn ethanol plant designs we expect could be built through 2022 using natural gas or biomass for process energy and employing advanced technology, in all cases, the midpoint and therefore the majority of the scenarios analyzed are above the $20 \%$ threshold. This indicates that, based on the current modeling approaches and sets of assumptions, we are over $50 \%$ confident the actual GHG performance of the ethanol from new corn ethanol

78. U.S. EnVtl. Prot. Agency, EPA-420-R-10-006, Renewable Fuel Standard Program (RFS2) REGULATORY IMPACT ANALYSIS 427 (2010).

79. Regulation of Fuels and Fuel Additives: Changes to Renewable Fuel Standard Program, 75 Fed. Reg. 14,670, 14,786 (Mar. 26, 2010) (to be codified at 40 C.F.R. pt. 80).

80. Id.

81. Id. 
plants will exceed the threshold of $20 \%$ improvement in lifecycle GHG emissions performance compared to the gasoline it is replacing. ${ }^{82}$

Why the different result from the proposed rule $?^{83}$ First, EPA made a number of assumptions about future corn ethanol plants. ${ }^{84}$ Second, EPA adjusted its estimates of ILUC on the basis of satellite photos of land use change in crucial areas. ${ }^{85}$ For purposes of this Article, these fig-

82. Id. EPA also explained:

In making the threshold determinations for this rule, EPA weighed all of the evidence available to it, while placing the greatest weight on the best estimate value for the base yield scenario. In those cases where the best estimate for the potentially conservative base yield scenario exceeds the reduction threshold, EPA judges that there is a good basis to be confident that the threshold will be achieved and is determining that the bio-fuel pathway complies with the applicable threshold. To the extent the midpoint of the scenarios analyzed lies further above a threshold for a particular biofuel pathway, we have increasingly greater confidence that the biofuel exceeds the threshold.

Id. at 14,785 .

83. EPA may have found these numbers intrinsically valid, or it may have received them favorably because it was under political pressure from Midwestern farm states to change its decision. If the latter were true, one might speculate that EPA deliberately engineered a result barely above the $20 \%$ threshold in order to signal its unhappiness and communicate that future decisions might not be as favorable. In any case, regardless of any behind-the-scene pressures, EPA had an obligation to give a reasoned explanation of its decision. It is worth considering whether its policy analysis was correct even though an important regulatory decision obviously may involve a mix of policy and politics.

84. As it explained:

EPA analyzed the lifecycle GHG performance of a variety of ethanol from corn starch pathways .... [The results presented here are for an average natural gas fired dry mill plant in 2022.]

$\cdots$

... [W] predict approximately $90 \%$ of all plants will be producing corn oil as a by-product either through a fractionation or extraction process; it is likely most if not all new plants will elect to include such technology.... We also expect that, to lower their operating costs, most facilities will sell a portion of their co-product DGS prior to drying thus reducing energy consumption and improving the efficiency and lifecycle GHG performance of the plant. The current national average plant sells approximately $37 \%$ of the DGS co-product prior to drying.

Id. at 14,785-86. The difference between dry milling and wet milling is explained in L. Leon Geyer, Phillip Chong \& Bill Hxue, Ethanol, Biomass, Biofuels and Energy: A Profile and Overview, 12 DRAKE J. AGRIC. L. 61, 69-70 (2007).

85. In its "factsheet" accompanying the rule, EPA explained the reasons for the improved results for corn ethanol:

- Based on new studies that show the rate of improvement in crop yields as a function of price, crop yields are now modeled to increase in response to higher crop prices. When higher crop yields are used in the models, less land is needed domestically and globally for crops as biofuels expand.

- New research available since the proposal indicates that distillers grains and solubles (DGS), a corn ethanol production co-product, is more efficient as an animal feed (meaning less corn is needed for animal feed) than we had assumed in the proposal. Therefore, in our analyses for the final rule, domestic corn demand and exports are not impacted as much by increased biofuel production as they were in the proposal analysis.

- Improved satellite data allowed us to more finely assess the types of land converted when international land use changes occur, and this more precise assessment led to a lowering of modeled GHG impacts. Based on previous satellite data, the proposal assumed cropland expansion onto grassland would require an amount of pasture to be replaced through deforestation. For the final rulemaking analysis we incorporated improved satellite data, as well as improved economic modeling of pasture demand, and found that pasture is also likely to expand onto existing grasslands. This reduced the GHG emissions associated with an amount of land use change. 
ures can simply be accepted. Engineers and forestry specialists may or may not have criticisms to offer, but a law journal would clearly be the wrong place to consider those issues.

What we care about is not the figures but the uncertainties surrounding them and whether EPA properly handled those uncertainties. In the next Part, we will consider EPA's treatment of uncertainty in depth. As we will see, EPA's analysis could be improved in several respects.

\section{PRobing EPA'S ANALYSIS OF ILUC}

All too often, the response to uncertainty is to ignore the problem in the hope that it will go away or that a solution will turn up on its own. Alternatively, advocates seize on their own version of the true magnitude of the hazard, as if there were no doubt about the facts. Neither approach produces intelligent analysis or sound policy. EPA deserves praise for eschewing these approaches and trying to come to grips with at least some of the uncertainties surrounding ILUC. ${ }^{86}$

The crux of EPA's analysis was to use the central estimate of emissions as the sole basis for decision. We will consider the appropriateness of this approach, asking several questions: Should EPA have taken into account the fact that the broad range of possible emission figures made its decision riskier? Should it have used a different central estimate (the mean, rather than the median)? Should it have taken into account the irreversibility of its decision in resolving the uncertainty? The answers to those questions offered below are respectively "no," "yes," and "yes."

\section{A. Risk Aversion}

EPA did not view the spread of possible values for ILUC as weighing against approval of corn ethanol, given that the best estimate within

\footnotetext{
U.S. ENVTL. PROT. AGENCY, EPA-420-F-10-006, EPA LifECyCLE ANALYSIS OF GREENHOUSE GAS EMISSIONS FROM RENEWABLE FUELS 3-4 (2010).

86. EPA specifically rejected the argument that it should ignore ILUC because the effects were uncertain:

While there is clearly significant uncertainty in determining the specific degree of land use change and the specific impact of those changes, there is considerable overall certainty as to the existence of the land use changes in general, the fact that GHG emissions will result, and the cause and effect linkage of these emissions impacts to the increased use of feedstock for production of renewable fuels.

Overall, EPA is confident that it is appropriate to consider the estimated emissions from land use changes as well as the other indirect emissions as "related to" the full fuel lifecycle, based on the reasonable technical basis provided by the modeling for the connection between the full fuel lifecycle and the indirect emissions, as well as for the determination that the emissions are significant. EPA believes uncertainty in the resulting aggregate GHG estimates should be taken into consideration, but that it would be inappropriate to exclude indirect emissions estimates from this analysis.
}

Regulation of Fuels and Fuel Additives: Changes to Renewable Fuel Standard Program, 74 Fed. Reg. 24,904, 25,024 (proposed May 26, 2009) (to be codified at 40 C.F.R. pt. 80). 
that range met the legal standard. Whether this was correct depends partly on the relevance of risk aversion to the decision.

People are often risk averse - that is, they prefer not to gamble. ${ }^{87}$ For instance, they may prefer a certainty of losing $\$ 1000$ in the form of paying an insurance premium rather than take a $1 \%$ chance of losing $\$ 90,000$. Yet if you do the arithmetic, you will see that in expected value terms, the premium costs more than the expected value of the loss. Economists explain this by saying that the utility of an additional dollar declines as wealth rises.8 ${ }^{88}$ This seems intuitively right - a homeless person would presumably care far more than a billionaire about the loss of a dollar.

The existence of insurance can be explained on the basis of risk aversion. Because of declining marginal utility, the dollars in the premium are less "valuable" than the dollars the policyholder would lose from an uninsured loss. Thus, paying a premium for insurance is justified even if the expected value of the insurance is a bit lower than the premium. The upshot is that what people care about (individually and as a society) is not the expected dollar value of a loss but its expected utility value. ${ }^{89}$ A risk-averse decision maker values a decision at less than the value of the expected outcome because of the risk associated with the decision. For most people, a bet that gives an equal chance of winning $\$ 10,000$ or losing $\$ 10,001$ is not worth taking.

The issue, then, is whether EPA should have upped its estimate of ILUC to account for risk aversion-or to put it another way, as insurance against the possibility that ILUC would turn out to be at the upper end of the range rather than the middle. Risk itself, in the form of a range of possible values for ILUC, might be a justification for a precaution. On the other hand, perhaps the only relevant factor is the average of the distribution of possible ILUC values.

To simplify the question, assume that considering ILUC, corn ethanol either reduces emissions $30 \%$ below gasoline or $10 \%$ below. Thinking only in terms of the climate benefits, this means that we are either a certain number of tons of carbon above the $20 \%$ point or the same amount below. Either one is beneficial in terms of climate benefits, but in any event, the amount is very small compared to total global emissions (meaning that the climate impacts are only at the margin). This analysis suggests that risk aversion should not be a significant factor, since the scale of the effects is so small relative to the overall costs of climate change. In essence, the scale of the bets is small, and society is making

87. Risk aversion is explained in STEVEN SHAVELL, ECONOMIC ANALYSIS OF LAW 52 (2004).

88. Paul Krugman \& Robin Wells, ECONOMiCS 548 (2d ed. 2009).

89. For further discussion of the techniques used by risk analysts, consult a standard text such as Daniel M. Kammen \& David M. HASSENZAHL, Should We Risk IT? Exploring Environmental, Health, and Technological Problem Solving (1999) or M. Granger MORGAN \& MAX HENRION, UNCERTAINTY: A GUIDE TO DEALING WITH UNCERTAINTY IN QUANTITATIVE RISK AND POLICY ANALYSIS (1990). 
many such bets in devising climate policies. There is little reason to purchase insurance in this situation.

By analogy, imagine that you are given a choice between betting on a $50 \%$ chance to win $\$ 1000$, versus a $25 \%$ chance to win $\$ 990$ combined with a $25 \%$ chance to win $\$ 1010$. (The $\$ 10$ one way or another in the hypothetical represents the difference between having $X$ amount of climate change if ILUC is low versus $X+\varepsilon$ if ILUC is high.) The difference does not seem significant. If you imagine making this bet many times-just as EPA makes many regulatory decisions - you would expect the law of averages to eliminate any real difference between the two bets.

On this analysis, risk aversion might well be a factor in dealing with the big issues of climate policy - whether to cap emissions and at what level. But at the margins, it may not make much difference. Thus, in making these marginal decisions, EPA is probably justified in ignoring the possibility that actual carbon impacts will be higher or lower than the average expected value.

\section{B. Feedback Loops and Asymmetrical Risks}

The range of uncertainties about ILUC is broad. It is also asymmetric because ILUC cannot go below zero but can go much higher than expected. Suppose, for example, that ILUC causes the destruction of forest. The first forest areas to be used would probably be those with the greatest possible crop yields. As demand for biofuels escalate, the remaining land would have lower yields, requiring that more of it be used up. In addition, once forest has been destroyed, nearby forest areas may be more accessible and easier to connect with markets, encouraging more destruction for agricultural purposes. It is easy to imagine a vicious circle taking hold.

This situation is characteristic of systems containing feedback effects." The amplification or "gain" of a system with feedback can be characterized as the input times $1 /(1-f)$, where $f$ is a measure of the strength of the feedback. Thus, $g(f)=1 /(1-f)$, where $g(f)$ represents the amount of gain for any given level of feedback. ${ }^{91}$ The output of the system is simply $g(f)$ times the input, so $g(f)$ measures the amplification due to feedback effects - like turning up a dial on a sound system.

90. Jianguo Liu et al., Complexity of Coupled Human and Natural Systems, 317 SCIENCE 1513, 1513-14 (2007).

91. Consider, for instance, a simple two-component system with a microphone and a loudspeaker. The microphone reduces the strength of the signal by a factor of $m$, the loudspeaker amplifies the sounds, then sends it back across the room to the microphone with its strength reduced by a factor of $l$. Let $f=l^{*} m$. Thus, each time the circuit is completed, the original signal is multiplied by $f$, it then goes through the circuit again where it comes out with strength $f^{2}$, etc. If this cycle is (nearly) instantaneous, the total amplification is $1+f+f^{2}+f^{3}+f^{4} \ldots=1 /(1-f)$ (by the algebra rule for summing geometric series). Lags in the process would complicate the results. Note that this formula applies only for $f<1$; if $f=1$ or $f>1$, the series diverges (or in simpler terms, the sum is infinite). 
The $g(f)$ function is sharply asymmetrical. Suppose, for example, that we think it is equally likely that $f=1 / 4$ and $f=3 / 4$. In other words, our best estimate is $f=1 / 2$, but with an uncertainty of $1 / 4$ on either side. If we were sure that $f$ was $1 / 2$, the "gain" from feedback effects would be $1 /(1-1 / 2)=2$. Given the uncertainty, we know that the gain is either $1 /(1-1 / 4)=4 / 3=1.33$, or $1 /(1-3 / 4)=4$. So the range of outcomes is very wide.

Feedback effects are not uniform: they depend on the input and thereby amplify uncertainties about the output. Notice that if $f$ is actually lower than our best estimate of $1 / 2$, the effect is rather modest. But if $f$ is higher, the effect is dramatic. In other words, uncertainty regarding the feedback parameter $f$ is really bad news when the feedback involves undesirable outcomes: the best-case scenario offers little solace compared with the most likely outcome, but the worst-case scenario is dramatically worse than the most likely outcome.92 This asymmetry follows from the fact that the graph of $1 /(1-f)$ is asymmetrical on the interval from 0 (where the value of the function is 1 ) to 1 (where the value of the function is infinite). Thus, feedback effects significantly expand the top end of the range rather than the middle or bottom, resulting in a skewed distribution.

It is important to be clear on the difference between the issues considered in this Section and the preceding one. The question in the preceding Section was whether EPA was justified in using its best estimate given that there was a broad range of possibilities; the question in this Section is whether EPA defined "best estimate" correctly as the median rather than the mean of the probability distribution.

Whether due to the lower bound of zero on ILUC or possible feedback effects, it seems clear that the probability distribution for ILUC is asymmetrical (which means that the mean and median are not equal). This is a serious problem in terms of EPA's methodology. Recall that EPA's justification for its decision was that there was at least a $50 \%$ chance that ILUC would be less than its estimate, meaning at least a $50 \%$ chance that corn ethanol met the $20 \%$ threshold. In short, EPA based its decision on the median of the probability distribution of ILUC. But a rational decision maker would base the decision on the mean, not the median. ${ }^{93}$

To see this, imagine the following $\$ 10$ bet on the role of a single die:

- If the die comes up with one spot or two spots, you win $\$ 15$.

- If the die comes up with three spots or four spots, you win $\$ 30$.

- If the die comes up with five spots or six spots, you lose $\$ 300$.

92. This result is explained in Margaret S. Torn \& John Harte, Missing Feedbacks, Asymmetric Uncertainties, and the Underestimation of Future Warming, 33 GEOPHYSICAL RES. LETTERS L10703 (2006).

93. Readers unfamiliar with the difference between the mean and median should check any statistics text-or more conveniently, try Wikipedia. 
Employing EPA's decision method, you would decide to take this bet. The median outcome is a win of $\$ 15$, which is a good return on a $\$ 10$ bet. Or to put it another way, there is better than a $50 \%$ chance that you would win at least something on the bet. If you took this bet repeatedly, however, you would expect to win $\$ 15$ a third of the time, win $\$ 30$ a third of the time, and lose $\$ 300$ a third of the time-meaning that on average, you lose $\$ 85$ each time you bet.

The trouble with EPA's method is that the outcomes are skewed. Again, simplifying the numbers makes the logic clearer. Suppose that EPA knew that, given ILUC, corn ethanol emissions are either $25 \%$ below gasoline or equal to gasoline - with the odds slightly favoring the first alternative. In other words, either corn ethanol is barely above the $20 \%$ threshold or fails very badly. EPA's argument would mean approving corn ethanol under those circumstances because the odds are slightly better than even that corn ethanol meets the threshold requirement. This would put EPA in the position of taking the bet in the previous dice scenario.

The skew in EPA's actual bet was not as extreme as in the simplified example, but given the fact that the median was only a hair's breadth above the critical $20 \%$ threshold, even a relatively small skew would push the mean below the threshold. ${ }^{94}$ If EPA were to make the same decision on similar factual records repeatedly for several different biofuels, it would approve all of them even though taken as a group, the fuels would be expected to produce less than the $20 \%$ emission reduction mandated by Congress.

The moral is clear. Decision makers should use the expected value (mean) outcome, not the median, as a decision-making standard.95

In response, EPA might argue that whether a fuel meets the $20 \%$ threshold is purely a factual determination, to which the policy consequences are irrelevant. But courts have recognized that in dealing with complex predictions at the frontiers of scientific knowledge, policy and science are not so easily disentangled, and that agencies are authorized to take a precautionary approach when the downside risks are large. ${ }^{96}$

94. EPA might respond that in any event, corn ethanol is highly likely to lead to at least some improvement in emissions, despite the concern that the improvement might be much smaller than Congress mandated. But Congress might have considered it worthwhile to force consumers to pay a higher price for renewable fuels only if those fuels produced big improvements. The further a fuel deviates from the $20 \%$ threshold, the less benefit is produced from the increased cost.

95. In the interest of simplicity, the statement in the text glosses over a complication. What the decision maker should really do is minimize the expected value of error costs. As argued in the previous Section, the situation should not implicate risk aversion, so the error costs should be proportional to the magnitude of the error. Thus, the decision that minimizes expected error costs is the one that minimizes the expected magnitude of the outcome.

96. See Indus. Union Dep't v. Am. Petroleum Inst., 448 U.S. 607, 656 (1980) ("[S]o long as they are supported by a body of reputable scientific thought, the Agency is free to use conservative assumptions in interpreting the data with respect to carcinogens, risking error on the side of overprotection rather than underprotection."); Am. Iron \& Steel Inst. v. EPA, 115 F.3d 979, 993 (D.C. Cir. 1997) ("II]t is within EPA's discretion to decide that in the wake of uncertainty, it would be better to give 


\section{Grandfathering, Irreversibility, and Lock-in Effects}

Another potential flaw in EPA's decision is that EPA took the level of uncertainty as fixed rather than taking into account the possibility of developing better information about ILUC. The possibility of acquiring relevant new information can significantly change standards for decision making. What economists call "hysteresis effects" can dramatically modify the results of a conventional cost-benefit analysis. ${ }^{97}$ Although the mathematical analysis is complex, the basic idea is not difficult to understand. If a decision has irreparable consequences, then it may be worth delaying the decision in order to obtain new information. Taking an irreversible step forecloses the possibility of future learning, and therefore incurs an extra cost that does not show up in the usual cost-benefit analysis. ${ }^{98}$ In a formal sense, waiting is equivalent to purchasing an option contract, and under many circumstances that option has positive value. Under some circumstances, taking this option value into account can change the standards for decision making. It is not unusual to find that an irreversible project should not be undertaken unless its expected benefits are twice as much as its cost. ${ }^{99}$ Otherwise, it is often better to wait for more information.

Given the magnitude of uncertainty and the likelihood of obtaining more information, hysteresis effects may be quite important in environmental law. Often, these effects push the balance toward environmental regulation. Destroying a rainforest or an endangered species is irreversible. Usually, whatever benefits can be obtained from the action will be available if we wait, and the uncertainty about costs will be reduced. Hence, there is a good argument for waiting while attempting to learn more.

"Real option" valuation provides a technique for analyzing hysteresis effects. ${ }^{100}$ Some policies may be desirable, apart from their direct ef-

the values a conservative bent rather than err on the other side."); Ethyl Corp. v. EPA, 541 F.2d 1, 3132 (D.C. Cir. 1976) (en banc) (stating that risk regulation involves policy judgments rather than simply factual determinations).

97. See Avinash Dixit, Investment and Hysteresis, 6 J. ECON. PERSP. 107, 119-20 (1992). The basic point is that "[w]here there is uncertainty, there may be learning." W. Kip Viscusi \& Richard Zeckhauser, Environmental Policy Choice Under Uncertainty, 3 J. ENVTL. ECON. \& MGMT. 97, 108 (1976).

98. For example, suppose that a project now has a $40 \%$ chance of producing a $\$ 1$ million loss, and a $60 \%$ chance of netting a $\$ 1$ million gain. This looks like a good investment, since the expected profit is $\$ 200,000$. On the other hand, suppose that by waiting six weeks, we can know the outcome of the investment with certainty. We will then invest in the project $60 \%$ of the time, for an expected gain of $\$ 600,000$, with no losses (since we will know not to invest in the loss situation). Hence, the value of waiting is $\$ 600,000$ minus $\$ 200,000$, or $\$ 400,000$. Even if we factor in the time value of money, waiting looks like the wise decision because making an immediate decision deprives us of the opportunity to obtain further information at a time when it can still do us some good.

99. See Dixit, supra note 97 , at 116 . See id. at 117,120 , for other examples of the magnitude of hysteresis effects.

100. For an explanation of real option theory and an application to climate policy, see Jon Anda, Alexander Golub \& Elena Strukova, Economics of Climate Change Under Uncertainty: Benefits of Flexibility, 37 ENERGY POL'Y 1345, 1347-49. (2009). Other applications of real option theory are dis- 
fects (or even despite their direct effects), because they keep open the option of making a better informed decision later. Much like the options traded in financial markets, the economic value of these options can be priced by taking into account the probability distribution of outcomes and the value of new information.

What is important here is not just irreversibility of a particular decision but the potential to obtain new information relevant to the decision. When we make an irreversible decision, we have lost the chance to use potential additional information to make a better decision later. In the case of EPA's decision regarding corn ethanol, the potential new information concerning ILUC could either show that ILUC is lower than currently expected, making corn ethanol a better biofuel, or worse, corn ethanol should not be considered a renewable fuel under EISA. EPA clearly intends to revisit the rule in the future based on improved methods and data. ${ }^{101}$

Lock-in effects provide a strong argument for being conservative in approving biofuels. ${ }^{102}$ Once a fuel is approved and plants are built, they provide a new market for corn, triggering ILUC. For instance, the price increase might trigger rainforest conversion in the Amazon. The release of carbon is irrevocable for as long as the plant is in operation because of the grandfathering provision of the statute (and for at least some time thereafter because it would take time for cropland to be reclaimed to its natural state). Indeed, if it appears that EPA might change its mind about ILUC, there is an incentive for firms to begin construction quickly on new plants in order to grandfather them. Given the possible regulatory lock-in effect and the difficulty of reversing land use conversion, EPA should err on the side of caution in approving biofuels.

This Part has probed EPA's treatment of ILUC uncertainty at the micro level. In Part III, we turn to some broader issues about whether ILUC is relevant to biofuels policy, whether uncertainty about ILUC is

cussed in Esther W. Mezey \& Jon M. Conrad, Real Options in Resource Economics, 2 ANN. REV. RESOURCE ECON. 33 (2010).

101. According to the EPA Factsheet for the RFS Regulation:

While EPA is using its current lifecycle assessments to inform regulatory determinations in this final rule, as required by EISA, we also recognize that as the state of scientific knowledge continues to evolve in this area, the lifecycle GHG assessments for a variety of fuel pathways will continue to be enhanced. Therefore, the Agency is committing to further reassess these determinations and lifecycle estimates. As part of this ongoing effort, we will ask for the expert advice of the National Academy of Sciences, as well as other experts, and incorporate their advice and any updated information we receive into a new assessment of the lifecycle GHG emissions performance of the biofuels being evaluated in this final rule. EPA will request that the National Academy of Sciences evaluate the approach taken in this rule, the underlying science of lifecycle assessment, and in particular indirect land use change, and make recommendations for subsequent lifecycle GHG assessments on this subject. This new assessment could result in new determinations of threshold compliance compared to those included in this rule. These would apply to future production from plants that are constructed after each subsequent rule incorporating a revised lifecycle assessment methodology.

U.S. ENVTL. PROT. AGENCY, supra note 85, at 4.

102. After making this point in my conference presentation, I discovered that Michael O'Hare and Richard Plevin have made the same argument in discussion. 
so great as to prevent its meaningful consideration, and how other steps might be taken to ameliorate ILUC.

\section{ILUC AND PUBLIC POLICY}

Part II got down in the weeds to analyze EPA's treatment of uncertainty in a specific regulatory proceeding, but ILUC also raises broader questions. Part III begins by addressing the question of whether ILUC should be considered in biofuels policy. There are some potential qualifications to the answer for other biofuels, but the answer for corn ethanol seems to be clear, as Section A explains. Section B addresses the specific argument that ILUC should be ignored because of limitations in our confidence about the reliability of models of ILUC. Finally, Section C considers policy responses that might ameliorate ILUC and narrow the range of uncertainty about its severity.

\section{A. The Relevance of ILUC}

Should ILUC be taken into account? There is a clear economic argument for doing so. The purpose of fostering biofuels is to moderate global climate change, which means reducing global emissions of greenhouse gases. If a particular fuel fails to serve this function because of ILUC, we should not encourage its production. Failing to take account of ILUC results in distorting investment in biofuels away from the fuels that will most efficiently and effectively meet the ultimate goal of climate mitigation. In the words of a report for California regulators coauthored by my late colleague Alex Farrell,

Although any attempt to calculate such values will be uncertain and open to debate, assigning zero emissions for global land use change clearly underestimates the effect. Hence, we believe a precautionary stance of assigning a non-zero value is appropriate because of the importance of providing signals and incentives to steer innovation and investment. ${ }^{103}$

Despite the obvious force of these arguments, some economists have suggested several counter-arguments. ${ }^{104}$

The crux of the main counter-argument is that ILUC would be adequately controlled if there were a perfect global carbon tax (so that conversion of land would have to pay for the resulting impact on climate change). Why should American biofuels producers be punished because

103. Daniel M. Kammen et al., Energy and Greenhouse Impacts of Biofuels: A Framework for Analysis, CTR. OF JOINT TRANSP. RESEARCH, 14 (Dec. 2007), http://www.internationaltransport forum.org/jtrc/DiscussionPapers/DiscussionPaper2.pdf. Alex was a brilliant young scholar in Berkeley's Energy and Resources Group who died tragically in 2008.

104. See Harry de Gorter \& David R. Just, Why Sustainability Standards for Biofuel Production Make Little Economic Sense, POL'Y ANALYSIS, Oct. 7, 2009, at 1, 7; David Zilberman, Gal Hochman \& Deepak Rajagopal, Indirect Land Use: One Consideration Too Many in Biofuel Regulation, AGRIC. \& RESOURCE. ECON. UPDATE, Mar.-Apr. 2010, at 1,1. 
the world community has failed to create such a tax? ${ }^{105}$ Doesn't it make "more sense to strive to enact policies that will make Brazil, or any other country, responsible for the GHG emissions associated with land-use changes in their countries through international agreement, rather than make agents in the United States, or elsewhere, responsible for the lack of action in Brazil"? ${ }^{106}$

It is undoubtedly correct that ILUC would become less significant and might be a marginal consideration the closer we come to an ideal and perfectly enforced international climate treaty. We do not seem to be close to a world treaty controlling all sources of greenhouse gases, and even if we had such a treaty, it is not clear that developing countries would be able to successfully control land use conversion by their inhabitants. In my view, even without a treaty, it is worth taking unilateral actions to reduce greenhouse gas emissions, because such actions can encourage international efforts, independently help slow climate change, and spur technological innovation. But the use of corn ethanol does not seem to fall into these categories of desirable unilateral actions. It involves established technology and contributes little to climate mitigation. U.S. support for corn biofuels is more likely to convince climate laggards of our regard for the interests of our farmers than to inspire them to join the fight against climate change. Corn ethanol needs to stand or fall on its merits, and for now it would be unrealistic to exclude ILUC in considering the climate benefits of this fuel. ${ }^{107}$

It is also an overstatement to say that consideration of ILUC results in punishing firms for conduct outside of their control. The only "punishment" is that they do not receive the benefit of special regulatory benefits aimed at promoting socially useful conduct (production of biofuels in order to reduce greenhouse gas emissions). It seems paradoxical to insist that we ought to provide those benefits even if we have good reason to believe that the resulting societal utility will not result. ${ }^{108}$

The nature of climate change undermines the argument that U.S. policymakers should only worry about effects that they themselves can

105. De Gorter \& Just, supra note 104 , at 7.

106. Zilberman et al., supra note 104 , at 2.

107. In contrast, it might be more reasonable to offer more advanced technologies a "free pass" on ILUC, at least during a trial period, in order to give them a chance to prove themselves. That issue, however, is outside the scope of this Article, especially given that other ways of promoting these technologies in their early stages might be more beneficial.

108. It is easy to think of parallel situations. For instance, increased safety standards for cars could raise the price, causing some consumers to own older, more dangerous cars longer, which would undermine the safety benefits of the requirements. This seems like a relevant consideration for policymakers, even though neither the agency nor the car manufacturers are responsible for the timing of the private consumption decisions of these car owners. Of course, if it is feasible to change consumer timing or to offset the price increase, the situation is different, and in any event, the effect may or may not be large enough to matter. As another example, consider the tendency of controls on carbon to lower the global price of fossil fuels, causing an offsetting increase in fossil fuel use elsewhere. This kind of "leakage" is endemic to carbon regulation. See, e.g., Steven Stoft, Renewable Fuel and the Global Rebound Effect (Global Energy Policy Ctr., Research Paper No. 10-06, 2010). 
control. It is one thing to say that our government should take action to improve the welfare of our citizens, even if people elsewhere may be harmed because of the market effects of our action. It is perhaps at least not unreasonable to say that our government's primary responsibility should be the care of its own citizens, and not worrying that our actions will intensify economic pressures toward harmful behavior in other countries that lack similarly vigilant governments. But greenhouse gases have the same impact on climate-within the United States and elsewhereregardless of where they are emitted. There is no benefit to Americans or anyone else by reducing emissions in the United States if those same emissions simply reappear elsewhere - at least not unless we have serious reasons for thinking that the United States emissions reductions will indirectly improve the prospects for global emissions limitations.

A second argument against considering ILUC is that it may be misleading to take into account some indirect effects of a decision without taking all such indirect effects into account (which is unlikely to be feasible)-and for similar reasons, misleading to consider the indirect effects of some decisions (production of biofuels) but not others (agricultural subsidies). ${ }^{109}$ Undoubtedly, trying to do a more comprehensive analysis might lead in the wrong direction unless we can do a completely comprehensive analysis. But it seems odd to take this possibility as an argument against improving policy analysis where we can, even if we cannot attain perfection by considering all of the potential ramifications of every single government decision.

A third argument is that consideration of ILUC adds to the uncertainty surrounding investments in biofuels research and production, thereby hindering the long-term effort for major strides in reducing carbon. ${ }^{110}$ The desire to provide a stable environment for investment is legitimate. But, it seems peculiar to do so at the expense of making investments responsive to social costs. For instance, why would we want investors to be indifferent to the difference between developing fuels that are likely to produce ILUC and those that are not? ${ }^{111}$

In EISA, Congress left EPA no choice about whether to consider ILUC. ${ }^{112}$ None of the arguments against this stance seem compelling. But even if ILUC is relevant, the question remains whether the uncertainties preclude its consideration. Nevertheless, the reasons why some critics feel troubled by inclusion of ILUC are understandable.

ILUC is an example of a larger phenomenon caused by the mismatch between the scale of climate change and the jurisdictional boundaries between governmental units. Ultimately, only coordinated action on a global scale can provide a satisfactory solution. But in the absence of a

109. De Gorter \& Just, supra note 104, at 3-4; Zilberman et al., supra note 104, at 3.

110. Zilberman et al., supra note 104 , at 4.

111. Note, in any event, that this argument has little application to a relatively mature technology such as corn ethanol.

112. See supra text accompanying notes $39-45$. 
centralized global government, which is not on the foreseeable horizon, coordination must take the form of voluntary international agreements and collaborative actions among a network of governmental, business, and nonprofit actors. ${ }^{113}$

ILUC is troublesome because of this network situation, leaving it unclear how much cooperation we can obtain from other countries on any given issue. ILUC would not present any intellectual puzzle if a global governing authority made biofuels rules. It also would not be a puzzle if we knew with certainty the only response to climate change would be unilateral action by one country. In that case, the country in question would clearly want to include ILUC in setting its biofuels policy - but on the other hand, a climate mitigation by only a single country would have only a marginal effect on climate change. We are in an unclear zone between global action and pure unilateralism, where we can reasonably expect some cooperative assistance from other countries but are not sure how much.

In this twilight zone between centralized global action and decentralized unilateralism, how we think about ILUC depends on whether, in the relevant time period, we have some confidence in an effective cooperative response. If we knew that developing countries could and would control land use change, then ILUC would not be a problem, but that seems a heroic assumption under current circumstances.

\section{B. ILUC and Model Uncertainty}

A final argument against considering ILUC deserves separate treatment because it is closely related to the issues considered in Part II. As Zilberman and his coauthors point out, estimating ILUC involves difficult economic modeling problems and predictions about ecosystem change. ${ }^{114}$ Some of these difficulties are captured by sensitivity analysis, which explores the effects of parameter changes on modeling outcomes. An example is provided by the confidence intervals for ILUC from corn ethanol developed by EPA and by Hertel and his coauthors. ${ }^{115}$ But these confidence intervals are based on specific models and cannot take into account the possibility that the models themselves are flawed-as is especially likely at an early stage of attempting to model a very complex phenomenon.

The term "model uncertainty" is sometimes used in this situation, where we have one or more models of the world but are unsure of which

113. See generally J.B. Ruhl \& James Salzman, Climate Change, Dead Zones, and Massive Problems in the Administrative State: A Guide for Whittling Away, 98 CALIF. L. REV. 59 (2010).

114. Zilberman et al, supra note 104, at 3.

115. See supra text accompanying note 62 . 
one is right. Dealing with model uncertainty is widely acknowledged to be difficult. ${ }^{116}$ Nevertheless, useful techniques do exist. ${ }^{117}$

Some significant research exists on how to make rational decisions when the distribution of probabilities is unknown. As economist Sir Nicholas Stern explains, in these models of uncertainty a decision maker, who is trying to choose which action to take, does not know which of several probability distributions is more or less likely for any given action. ${ }^{118} \mathrm{He}$ explains that it can be shown that a decision maker

would act as if she chooses the action that maximises a weighted average of the worst expected utility and the best expected utility.... The weight placed on the worst outcome would be influenced by concern ... a about the magnitude of associated threats, or pessimism, and possibly any hunch about which probability might be more or less plausible. ${ }^{119}$

These models are sometimes called $\alpha$-maxmin models, with $\alpha$ representing the weighting factor between best and worst cases. ${ }^{120}$ One way to understand these models is that we might want to minimize our regret if we make the wrong decision, where we regret disastrous outcomes that lead to the worst-case scenario but we also regret having missed the opportunity to achieve the best-case scenario. Alternatively, $\alpha$ can be a measure of the balance between our hopes (for the best case) and our fears (of the worst case). ${ }^{121}$

We can get at least get a better sense of the import of uncertainty through such an analysis. For purposes of illustration, let us take the

116. See NAT'L RESEARCH COUNCIL, NAT'L ACAD. SCIS., SCIENCE AND DECISIONS: AdVANCING RISK ASSESSMENT 105-06 (2009) ("One of the dimensions of uncertainty that is difficult to capture quantitatively (or even qualitatively) involves model uncertainty.").

117. See Farber, supra note 9, for a discussion of model uncertainty and methods for dealing with it.

118. Nicholas Stern, The Economics of Climate Change: The Stern Review 39 (2006). For discussion of the so-called $\alpha$-maxmin model in the context of a more general theory, see Paolo Ghirardato, Fabio Maccheroni \& Massimo Marinacci, Differentiating Ambiguity and Ambiguity Attitude, $118 \mathrm{~J}$. ECON. THEORY 133, 153-55 (2004) (see especially proposition 19(ii) on page 154). $\alpha$ Maxmin can be derived from the assumption that decision makers are indifferent between acts which result in the same range of expected utilities over the set of scenarios. See Paolo Ghirardato, Fabio Maccheroni \& Massimo Marinacci, Ambiguity from the Differential Viewpoint 6 (Cal. Inst. of Tech. Div. of Humanities and Soc. Sci., Working Paper No. 1130, 2002). If decision makers care only about the utility associated with outcomes, the assumption seems plausible if we assume that the decision maker has no ability or willingness to evaluate the likelihood of different scenarios, so outcomes across scenarios only reflect the range of possibilities.

119. STERN, supra note 118 , at 39 .

120. A key point in applying these models is identifying the best and worst case scenarios. Use of the model might encourage interest groups to put forward exaggerated scenarios (although this is probably already an incentive for other reasons).

121. Some economists and finance theorists postulate that risk measures should focus primarily on adverse outcomes, a concept known as downside risk, with less weight on the uncertainty created by the possibility of a better than expected outcome. See MichaEl Hanemann et al., Cal. Climate Change CTR., Climate Change Impacts to URban and Agricultural Sectors in CALIFORNIA 36-41 (2008) (on file with author) (describing theories of downside risk). The magnitude of $\alpha$ can be considered a measure, in the uncertainty context, of the weight placed on downside outcomes. A high $\alpha$ indicates an aversion to "downside uncertainty." 
"best case" of ILUC to be zero and the "worst case" to be Searchinger's estimate of $104 \mathrm{gCO}_{2} / \mathrm{MJ}^{122}$ Converted to $\mathrm{gCO}_{2} / \mathrm{MJ}^{123} \mathrm{EPA}$ 's estimate for gasoline emissions was 93 (with a cutoff of 74.5 for the required $20 \%$ reduction), while its best estimate for ILUC was 30.4 and for overall corn ethanol emissions 75. ${ }^{124}$

It is apparent that, for any $\alpha$ above a third, ILUC will rise significantly above EPA's estimate - and given that in EPA's analysis, corn ethanol barely squeaked by the $20 \%$ requirement, this means that corn ethanol would not qualify. For instance, if we use an $\alpha$ of .5 , weighting the best case and worst case equally, we come up with an ILUC of 52 $\mathrm{gCO}_{2} / \mathrm{MJ}$. This is 21.6 above EPA's estimate of ILUC, raising overall emissions from 75 to $96.6 \mathrm{gCO}_{2} / \mathrm{MJ}$. This would place total emissions for corn ethanol (including ILUC) above total emissions for gasoline-far away from the $20 \%$ reduction required by Congress. The upshot is that in order to approve corn ethanol, we have to be quite optimistic about ILUC and willing to gamble that the true model would produce a figure that is well at the lower end of the scale rather than the higher end. ${ }^{125}$

It is important to keep this analysis in perspective. The $\alpha$-maxmin analysis is addressed to the argument that we should have little confidence in any of the current models. Taking the Searchinger model as the highest result we are likely to see is actually a favorable assumption from the point of view of corn ethanol because we cannot be sure that his is the upper bound of the possible magnitude of ILUC. The other assumption is that the best case for ILUC is zero, whereas it seems likely that at least some degree of indirect land use conversion would take place. Yet, even making these favorable assumptions, if uncertainty about modeling is otherwise high, EPA would have to be highly optimistic about the true value of ILUC in order to approve corn ethanol if model uncertainty is large.

Thus, even if we have a relatively weak sense of the reliability of current ILUC models, we can still gain some useful insights into decision making. The indication is that corn ethanol is a bad bet in terms of meeting the renewable fuels threshold even if we have considerable uncertainty about what model of ILUC is right.

122. See supra text accompanying notes $65-68$ (Table).

123. The conversion factor from EPA's BTU $/ \mathrm{kg}$ units is 0.95 .

124. Regulation of Fuels and Fuel Additives: Changes to Renewable Fuel Standard Program, 75 Fed. Reg. 14,670, 14,788 (Mar. 26, 2010) (to be codified at 40 C.F.R. pt. 80). This is actually slightly above the cutoff by my calculation from EPA's table, but that is presumably due to rounding errors. Using EPA's BTU-based units, the gasoline emissions figure is 98 , and $80 \%$ of 98 equals 78.4 , while EPA reports an emissions figure of 79 for ethanol, slightly above the cut-off.

125. Even if we are twice as inclined toward the best case than the worst case, ILUC would come out at 34.6 (a third of Searchinger's estimate), adding 4.2 to the EPA estimate for overall corn ethanol emissions, bringing total emissions well over the cutoff point. 


\section{Policy Responses to ILUC Uncertainty}

As Zilberman and his coauthors point out, ILUC "can also be influenced by policy choices; for example, more investment in agricultural research, more liberal regulation of biotechnology, or changes in the deforestation and land-use policies." 126 The policy options provide ways of limiting ILUC in the future, although they are not relevant to the decisions that EPA must make currently about biofuels.

One set of options is to increase yields, either by allowing greater use of existing genetically modified organism (GMO) crops or by developing new plant varieties through research. This is not, of course, an option that is open to EPA, but Congress could (and should) take more vigorous action to promote the development of higher yield crops. ILUC provides a strong environmental argument for strengthening efforts to increase crop yields in order to offset whatever land is used to produce biofuels. Even apart from biofuels, the need to feed an increasing world population will result in conversion of forests and grasslands to food production, resulting in carbon releases as well as other possible environmental harms such as loss of biodiversity. Increased yields should not be cynically dismissed as just a benefit to agribusiness; they are also important for the world environment as well as addressing world hunger.

Freezing the conversion of natural areas to food production may be difficult. It may also be inhumane given the need to feed a larger world population. But it seems more practical to try to shape land conversion away from areas of high environmental value. Among other benefits, this would reduce the level of emissions from ILUC even if the acreage remained the same. If unused land is going to be converted to cropland because of price pressures from biofuels, we should work with governments of developing countries to try to ensure that rainforests and prairie are avoided.

The potential for ILUC should also shape the direction of research for biofuels. We should place a premium on potential biofuels that have minimal agricultural footprints. The use of algae seems ideal, but certain cellulosic biofuels may not be far behind. The best solution to ILUC is to devise biofuels that do not rely on existing croplands or on conversion of other valuable lands to the production of biomass for biofuels.

Given the potential for ILUC, biofuels mandates should be designed carefully. It may be a mistake to focus exclusively on liquid biofuels as substitutes for gasoline. The use of biomass to produce electricity may be more efficient, combined with greater use of electric vehicles. ${ }^{127}$ California's Low Carbon Fuel Standard has the advantage of allowing use of electricity as an alternative to liquid fuels as a means of

126. Zilberman et al., supra note 104 , at 3 .

127. See Tyler Hamilton, Biofuels vs. Biomass Electricity, TECH. REVIEw (May 8, 2009), http://www.technologyreview.com/energy/22628. 
moving away from petroleum. ${ }^{128}$ The potentially greater efficiency of this use of biomass has to be balanced, however, against the ability of liquid biofuels to produce carbon reductions from existing portions of the vehicle fleet.

Regulatory agencies do not have the luxury of considering these broader options, and they should not shape their own decisions based on speculation that Congress or others might take future steps to ameliorate ILUC. But decision makers with broader responsibilities should consider measures to ensure that the use of biofuels causes the least possible emissions of carbon from conversion of land to crop production.

\section{CONCLUSION}

By all appearances, EPA made a serious and sustained effort to deal with the problem of ILUC. The modeling issues are formidable, and EPA appears to have acted responsibly and in good faith. Nevertheless, EPA's determination regarding ILUC for corn ethanol appears to involve significant errors of judgment in its treatment of uncertainty. Most notably, EPA erred by basing its decision on the median value of predicted ILUC rather than the statistical mean. EPA was importantly right, however, not to be dissuaded by uncertainty from taking ILUC seriously.

The precise circumstances of EPA's 2010 determination of corn ethanol ILUC are unlikely to be repeated. But there are some important lessons for the future. First, in making such determinations under existing law, EPA should be more sophisticated in its treatment of uncertainty. It should use the means of probability distributions rather than medians; it should take into account lock-in effects and consider real option values; and it should give explicit attention to model uncertainty, possibly through use of $\alpha$-maxmin to test the significance of model uncertainty. Given the closeness of the decision to approve corn ethanol as a renewable fuel, a more sophisticated treatment of uncertainty would likely have changed the outcome.

Second, EPA was correct to proceed with a consideration of ILUC despite the admitted degree of uncertainty regarding the magnitude of ILUC. The basic point is simple: the fact that we do not know a number precisely is no reason to treat it as zero. Although we do not know the amount of ILUC from corn ethanol with any precision, we do know that it is almost certainly greater than zero and large enough to be a significant factor in the overall life-cycle assessment of corn ethanol. EPA could not responsibly just close its eyes to these facts and pretend the

128. CAL. OFFICE OF THE Governor, THE ROLE OF a LOW CARBON Fuel STANDARD IN REducing GREenhouse GAS EMISSIONS AND PROTECTING OUR ECONOMY 5 (2007), http://files.eesi.org/lcfs_white_paper_version_18_final.pdf. California may be changing its stance regarding corn ethanol in light of new research indicating that corn ethanol has not reduced U.S. corn exports. See OLADOSU \& KLINE, supra note 2. 
ILUC did not exist. EPA did take ILUC into account and deserves credit for doing so.

Other federal agencies have not always done as well-consider the Nuclear Regulatory Commission's (NRC) refusal to consider the possible effects of terrorism at nuclear power plants on the ground that it could not quantify the risk. ${ }^{129}$ As the U.S. Court of Appeals for the Ninth Circuit explained in rejecting the NRC's policy, this position is indefensible under the relevant statute, the National Environmental Policy Act (NEPA): "If the risk of a terrorist attack is not insignificant, then NEPA obligates the NRC to take a 'hard look' at the environmental consequences of that risk." 130 The court added that the "NRC's actions in other contexts reveal that the agency does not view the risk of terrorist attacks to be insignificant" and "[p]recise quantification is therefore beside the point." ${ }^{\prime 31}$ These observations are also applicable to ILUC, the difference being that EPA refused to adopt the NRC's oblivious attitude.

Finally, the ILUC issue suggests some other policy changes, such as placing a strong emphasis on increasing crop yields (and thereby indirectly limiting ILUC). The problem of ILUC needs to be placed in the broader context of how we feed a burgeoning world population without destroying rainforests and grasslands. We need to do whatever is possible to avoid a choice between the evils of climate change and widespread malnutrition.

The question of whether EPA correctly took account of uncertainty in making a single regulatory decision about a single biofuel may seem narrow. The decision in question, however, will have significant impacts on the biofuels industry, U.S. agriculture, and global greenhouse gas emissions. It may also harm the world's hungriest citizens, although world hunger was not necessarily within EPA's jurisdiction. Moreover, the methodology used to make this decision will help shape the future of biofuels. These are not insignificant issues.

At a higher level of generality, the appropriate treatment of uncertainty is a pervasive problem in policy making. Through an in-depth analysis of one important regulatory decision, we can gain insights into the broader issue of regulatory uncertainty. Regulators must operate in an uncertain world, but they need not operate blindly.

129. San Luis Obispo Mothers for Peace v. Nuclear Regulatory Comm'n, 449 F.3d 1016, 1032 (9th Cir. 2006).

130. Id.

131. Id. 


\section{APPENDIX ${ }^{132}$}

LIFECYCLE ESTIMATES FOR CORN ETHANOL ${ }^{133}$

Table V.C.-1-Lifecycle GHG Emissions for Corn Ethanol, 2022

[kg CO, $\mathrm{e} / \mathrm{mmBTU}]$

\begin{tabular}{|c|c|c|}
\hline Fuel ypo & Ethanod & $\begin{array}{l}2005 \text { Gaso } \\
\text { line beselino }\end{array}$ \\
\hline 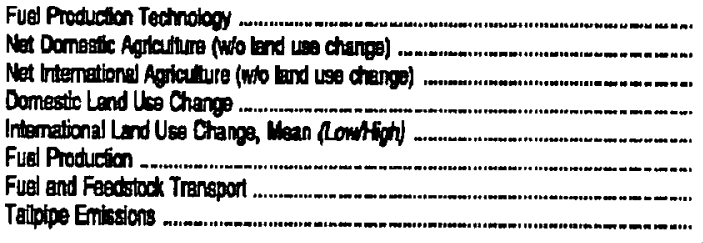 & 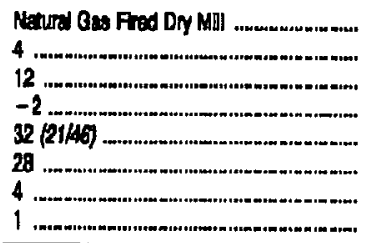 & 19 \\
\hline Tobal Emibstors, Maen (Lowits & $78(54 B\rangle)$ & 98 \\
\hline
\end{tabular}

\section{UNCERTAINTIES IN LIFECYCLE EMISSIONS ANALYSIS ${ }^{134}$}

Figure 2.6-1. Distribution of Results for a New Natural Gas Fired Corn Ethanol Plant Average 2022 Plant: Natural Gas, 63\% Dry, 37\% Wet DGS (w/ Fractionation)

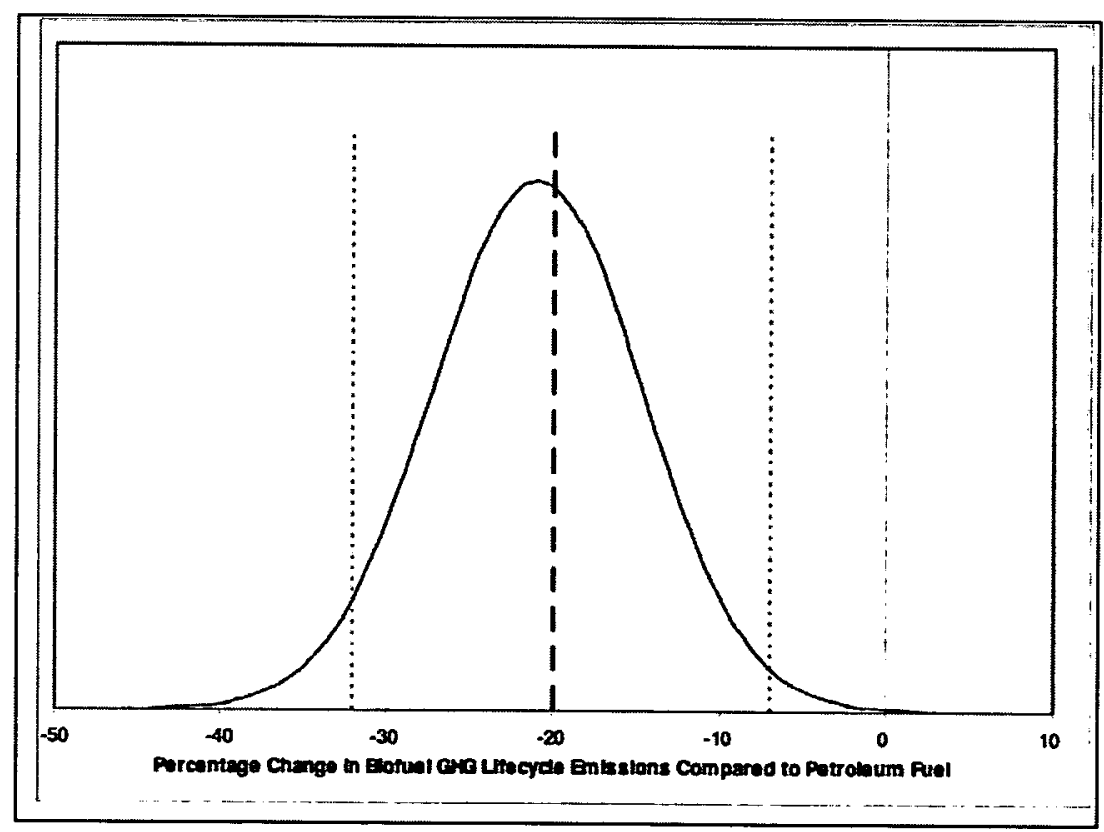

132. U.S. ENVTL. PROT. AgENCY, supra note 78, at 427.

133. Regulation of Fuels and Fuel Additives: Changes to Renewable Fuel Standard Program, 75 Fed. Reg. 14,670, 14,788 (Mar. 26, 2010) (to be codified at 40 C.F.R. pt. 80).

134. Id. at 14,787 . 